\title{
Evaluation of Long Stress-Induced Non-coding Transcripts 5 Polymorphism in Iranian Patients with Bladder Cancer
}

\author{
Mahla Nazari ${ }^{1}$, Mahboobeh Nasiri ${ }^{1,2^{*}}$, Abbas Ghaderi ${ }^{3}$ \\ ${ }^{1}$ Department of Biology, Islamic Azad University, Arsanjan Branch, Arsanjan, Iran. \\ ${ }^{2}$ Young Researchers and Elite Club, Islamic Azad University, Arsanjan Branch, Arsanjan, Iran. \\ ${ }^{3}$ Shiraz Institute for Cancer Research, Shiraz University of Medical Sciences, Shiraz, Iran.
}

Received: 27 Apr 2016

Revised : 18 May 2016

Accepted: 10 Jun 2016

Corresponding Author:

Mahboobeh Nasiri

Department of Biology, Islamic Azad

University, Arsanjan Branch,

University Blvd., Arsanjan, Fars.

Phone: +98-71-43523907-9

E-mail: nasiri@iaua.ac.ir

\begin{abstract}
Background: Bladder cancer (BC) is the most commonly diagnosed genitourinary cancer in Iran, presented in both men and women. BC is a multifactorial trait resulting from the complex interaction between several genes and environmental factors. Long stress-induced non-coding transcript 5 (LSINCT5), a member of the long non-coding RNAs, is abundantly expressed in high proliferative cells, as well as the cells vulnerable to cellular stress in response to chemical carcinogens.

This case-control study aimed to determine any association between LSINCT5 rs2962586 polymorphism and bladder cancer.

Materials and Methods: A group of 150 patients with $\mathrm{BC}$ were compared with 143 subjects as a control group. Genotyping of the rs2962586 polymorphism was done using tetra- primer amplification refractory mutation system-polymerase chain reaction (T-ARMS PCR) method.

Results: Genotype and allele distribution were not significantly different between the case and control groups. Smoking was found to be the confounding risk factor for bladder cancer.

Conclusion: Considering the result of our analyses, it seems that LSINCT5 could not affect individual susceptibility to BC among Iranian patients, however, it can be considered as a disease predictor among smokers.
\end{abstract}

Keywords: Bladder cancer; Long stress-induced non-coding transcript 5; Polymorphism

Please cite this article as: Nazari M, Nasiri M, Ghaderi A. Evaluation of Long Stress-Induced Non-coding Transcripts 5 Polymorphism in Iranian Patients with Bladder Cancer. Res Mol Med. 2016; 4 (3): 17-21

\section{Introduction}

Bladder cancer (BC) is the fourth most common cancer in men and second urological malignancy after prostate cancer $(1,2)$. In clinical stage, BC patients may be broadly subdivided into two groups: those having a non-muscle-invasive bladder cancer (NMIBC), categorized in stages $\mathrm{Ta}$ and $\mathrm{T} 1$, and those with a muscle-invasive disease (MIBC), stages $\mathrm{T} 2$ to $\mathrm{T} 4$. Histologically, the $\mathrm{BC}$ is divided into urothelial cell carcinoma (UCC, previously called transitional cell carcinoma, TCC), squamous cell carcinoma (SCC), adenocarcinoma, and other sporadic lesions (3). The etiopathogenesis of BC is still unclear, but various predisposing factors, including male gender, tobacco use and occupational exposure to some suggested (4-6).
Special chemicals, along with genetics have been non-coding RNAs, especially long non-coding RNAs (LncRNAs), are one of the most recent interests of scientists as underlying pathophysiology for human cancers (7). Genome-wide association studies (GWAS) and transcriptional profiling provided a link between the aberrant expression of IncRNAs and the pathogenesis/prognosis of cancers (8-10). LncRNAs have been defined as a group of non-coding RNAs in a range length from 200 nucleotides to 100 kilobases. LncRNAs are mostly transcribed by the enzyme RNA polymerase II and are polyadenylated as well as mRNA (11). Long stress-induced non-coding transcripts 5 (LSINCT5, gene ID: 101234261; 
5p15.33) belongs to a novel family of stress-induced lncRNAs with 12 members (LSINCT1-12) and seems to play a role in cellular proliferation and cancer development, especially in response to oxidative damage by carcinogens $(12,13)$. Despite other lncRNAs, the LSINCT5 is transcribed by RNA polymerase III transcription enzyme with differential expression in different tissues based on their proliferation rate (14). However, little information is available on the expression pattern of LSINCT5 in bladder cancer, and whether the aberrant expression of LSINCT5 in bladder cancer is associated with malignancy, metastasis, or prognosis remains unknown.

This investigation was performed on a group of patients with $\mathrm{BC}$, so as to evaluate the associations of LSINCT5 rs2962586T/C polymorphism with bladder cancer.

\section{Materials and Methods Subjects}

One hundred fifty patients with bladder cancer (mean age $\pm \mathrm{SD}$; $62.87 \pm 12.39$ years) enrolled in this casecontrol study. The diagnosis was made by urologist considering the symptoms such as gross hematuria, careful physical examination, and results of urine analysis, culture and urine cytology followed by ultrasonography and CT scan of the urinary system. The diagnosis was later confirmed using cystoscopy. DNA samples were provided from Shiraz Institute for Cancer Research (ICR), Shiraz University of Medical Sciences, School of Medicine. One hundred fortythree unrelated healthy subjects $(62.50 \pm 11.24$ years $)$ participated in the control group. Age, gender, and ethnic-matched controls were from the same institute in Shiraz University of Medical Sciences.

Table 1. LSINCT5 rs2962586 SNP and primers.

\begin{tabular}{|c|c|c|c|}
\hline SNP & Location & sequence & MAF \\
\hline \multirow[t]{4}{*}{ rs2962586 } & Chr.5:2712824 & OF: ATAAACCAGAAAGGACAGAAATAGAC & 0.48 \\
\hline & & OR: CTCTCTCAATACCAGCGACA & \\
\hline & & IF: CTCAACGGAACCGAGGAT (T allele) & \\
\hline & & IR: ATTGTTGCTTTTCCAAGTAGG (C allele) & \\
\hline
\end{tabular}

OF; outer forward primer: a non-specific external forward primer; OR; outer reverse primer: a non-specific external reverse primer; IF: an inner specific forward primer for detection of the "T" allele; IR: an inner specific reverse primer for detection of the "C" allele. MAF: minor allele frequency.

\section{Genotyping}

Extracted DNA was obtained from the DNA bank in Shiraz Institute for Cancer Research. LSINCT5 rs2962586T/C genotyping was performed using tetraprimer amplification refractory mutation systempolymerase chain reaction (T-ARMS PCR). Each PCR reaction was done in a total volume of $13 \mu 1$, containing $1 \mu \mathrm{l}$ genomic DNA, 6.25 $\mu \mathrm{l}$ PCR master mix (Yekta Tajhiz Azma, Iran), $2.75 \mu$ l deionized water, and $0.75 \mu \mathrm{l}$ of each primer. Amplification of the selected region was carried out following the cycling program of pre-denaturation at $95{ }^{\circ} \mathrm{C}$ for 5 min, followed by 35 cycles of denaturation at $94{ }^{\circ} \mathrm{C}$ for $45 \mathrm{sec}$, annealing at $57{ }^{\circ} \mathrm{C}$ for $45 \mathrm{sec}$, and extension at $72{ }^{\circ} \mathrm{C}$ for $45 \mathrm{sec}$, with a final extension at $72{ }^{\circ} \mathrm{C}$ for $7 \mathrm{~min}$. PCR products were resolved on rs2962586T/C polymorphism and the primers used in the study are listed in Table 1.

\section{Ethics Statement}

Written informed consents were obtained from all participants according to the guidelines of the Ethics Committee of Shiraz University of Medical Science, School of Medicine.

\section{Statistical analysis}

The SPSS software (Statistical Package for the Social Sciences, version 16.0, SPSS Inc, Chicago, USA) was used for data management and analysis.

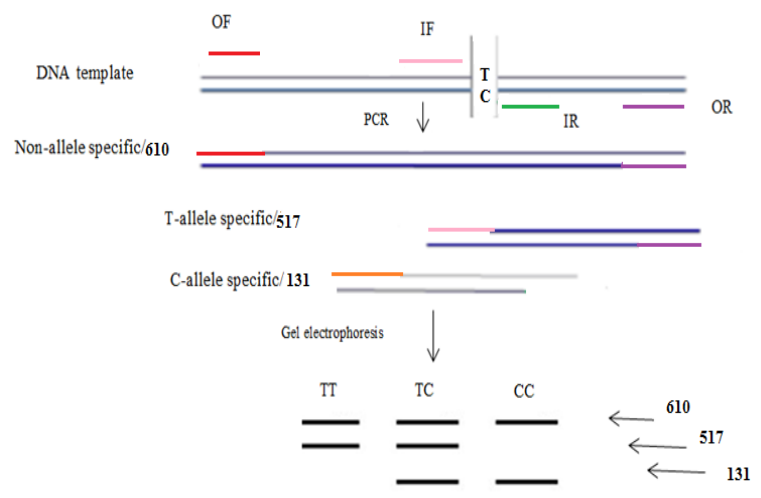

Figure 1. Schematic representation of the T-ARMS PCR method for genotyping the LSINCT5 rs2962586 polymorphism. As the result of the amplification show, the $610 \mathrm{bp}$ fragment is an internal control confirming the occurrence of amplification, the $517 \mathrm{bp}$ amplicon is the result of the presence of $\mathrm{T}$ allele, while $131 \mathrm{bp}$ fragment show is related to $\mathrm{C}$ allele. The presence of both 571 and $131 \mathrm{bp}$ amplicons is the result of heterozygote genotype CT. 
The comparison between cases and controls was done using t-test and Pearson's Chi-square test for continuous and nominal variables, respectively. The Chi-square test was also used to compare the distribution of genotype frequencies with those expected from Hardy-Weinberg equilibrium (HWE). The allele and genotype frequencies were calculated using direct gene counting and the results were compared with the controls using logistic regression analysis. The odds ratio and $95 \%$ confidence interval were calculated to estimate the strength of the associations. $\mathrm{P}$ values less than 0.05 were considered significant.

Table 2. Clinical characteristics of patients with bladder cancer.

\begin{tabular}{|c|c|c|c|c|}
\hline Variables & Cases $(n=150)$ & Controls $(n=143)$ & $\mathbf{P}^{*}$ & OR(95\%CI) \\
\hline Mean age $($ year $\pm \mathrm{SD})$ & $62.87 \pm 12.39$ & $62.50 \pm 11.24$ & & \\
\hline $\begin{array}{l}\text { Sex } \\
\text { Male }\end{array}$ & $107(71.30) \dagger$ & $131(91.60)$ & & \\
\hline Female & $43(28.70)$ & $12(8.40)$ & & \\
\hline Smokers & $17(15.30)$ & $104(74.80)$ & $<0.001$ & $16.43(8.63-31.25)$ \\
\hline $\begin{array}{l}\text { Tumor type } \\
\text { UCC }\end{array}$ & $118(78.67)$ & - & & \\
\hline $\mathrm{SCC}$ & $7(4.67)$ & - & & \\
\hline $\mathrm{AC}$ & $1(0.66)$ & - & & \\
\hline Unknown & $24(16.00)$ & - & & \\
\hline $\begin{array}{l}\text { Tumor grade } \\
\text { G1 }\end{array}$ & $5(3.33)$ & - & & \\
\hline G2 & $38(25.33)$ & - & & \\
\hline G3 & $61(58.70)$ & - & & \\
\hline Unknown & $46(30.66)$ & - & & \\
\hline $\begin{array}{l}\text { Muscle invasive } \\
\text { Yes }\end{array}$ & $49(32.66)$ & - & & \\
\hline No & $34(22.66)$ & - & & \\
\hline Unknown & $67(44.66)$ & - & & \\
\hline
\end{tabular}

\section{Results}

The performance of the primers is demonstrated in Figure 1. Baseline characteristics of the included subjects are shown in Table 2. The frequency of the disease was significantly higher in men than women (2.5-fold). We found smoking as the potential risk factor for BC (OR: 16.43,95 \%CI: 8.63-31.25,P<0.001). The genotype frequencies of $\mathrm{rs} 2962586$ polymorphism in controls $\left(\chi^{2}=1.96, \mathrm{df}=1\right.$, and $\left.\mathrm{P}>0.05\right)$ and patients $\left(\chi^{2}=0.99\right.$, df $=1$, and $\left.\mathrm{P}>0.05\right)$ were consistent with the Hardy-Weinberg equilibrium distribution.

Table 3 shows the allele and genotype distribution of the studied polymorphism between the case and control groups. The frequency of polymorphic allele $\mathrm{T}$ was slightly higher in cases compared with the controls $(0.19$ vs. 0.15$)$ however, this difference was not significant $(\mathrm{P}=0.14)$. The frequency of TT $(3.30$ vs. $1.4 ; \mathrm{P}=0.25)$ and $\mathrm{TT}+\mathrm{CT}(35.30$ vs. $28.00 ; \mathrm{P}=$ 0.17) genotypes was also higher among cases compared with the controls, while this difference was shown not to be statistically significant. Regarding the influence of smoking on the risk of $\mathrm{BC}$, a separate analysis was done to detect the association of rs2962586 polymorphism in smokers and nonsmokers (Table 4). A significant association was detected between rs2962586 and smoking habit in the comparison between cases and controls $(\mathrm{P}=0.01)$.

\section{Discussion}

Recent studies have revealed the contribution of lncRNAs such as H19, UCA1/CUDR and ncRAN in the pathogenesis of bladder cancer (15-17). Silva et al. in 2010 found a new family of long non-coding RNAs, named LSINCT1-12, whose expression was significantly high in rapidly growing tissues or tissues that are prone to cellular stress (13). Almost $90 \%$ of the BCs are the transitional cell carcinomas, involving the transition cells with a high rate of proliferation and in close contact with waste products in the urine that may cause cancer by promoting cellular proliferation, such as chemicals in cigarette smoke (18). 
Table 3. Distribution of allele and genotype frequencies in cases and control.

\begin{tabular}{|c|c|c|c|c|}
\hline rs2962586 & $\begin{array}{c}\text { BC } \\
(n=150)\end{array}$ & $\begin{array}{l}\text { Controls } \\
(\mathrm{n}=143)\end{array}$ & p value & $\begin{array}{c}\text { Odds Ratio }{ }^{*} \\
(95 \% \text { confidence interval })\end{array}$ \\
\hline \multicolumn{5}{|l|}{ Co-dominant } \\
\hline $\mathrm{CC}$ & $97(64.7)$ & $103(72.00)$ & - & Reference \\
\hline $\mathrm{TC}$ & $48(32.00)$ & $38(26.60)$ & 0.26 & $1.34(0.81-2.23)$ \\
\hline TT & $5(3.30)$ & $2(1.40)$ & 0.25 & $2.65(0.50-14.00)$ \\
\hline \multicolumn{5}{|l|}{ Dominant ( $\mathrm{T}$ allele) } \\
\hline $\mathrm{TC}+\mathrm{TT}$ & $53(35.30)$ & $40(28.00)$ & 0.17 & $1.41(0.86-2.31)$ \\
\hline \multicolumn{5}{|l|}{ Alleles } \\
\hline $\mathrm{C}$ & $242(0.81)$ & $244(0.85)$ & - & Reference \\
\hline $\mathrm{T}$ & $58(0.19)$ & $42(0.15)$ & 0.14 & $0.72(0.46-1.11)$ \\
\hline
\end{tabular}

* Logistic regression; $\mathrm{p}$ value $<0.05$ is considered significant.

Regarding this and the fact that ovary and breast share some characteristics with bladder, in this study, for the first time, the association between LSINCT5 rs2962586 polymorphism and bladder cancer was investigated. No significant difference was found in frequencies of alleles and genotypes among patients with $\mathrm{BC}$ and healthy controls, while comparison of the genotypes between smokers and non-smokers showed a higher frequency of BCs among smokers. These findings are consistent with previous reports based on an increased LSINCT5 expression in breast cell lines exposed to NNK, the most active carcinogen of cigarette smoke $(12,13)$.

Table 4. Association of the lsinct5 rs 2962586 with BC regarding the smoking condition.

\begin{tabular}{lcccc}
\hline \multirow{2}{*}{ Risk factor } & \multicolumn{2}{c}{ Cases $(\mathrm{n}=150)$} & \multicolumn{2}{c}{ Controls $(\mathrm{n}=143)$} \\
& $\mathrm{CC}$ & $\mathrm{CT}+\mathrm{TT}$ & $\mathrm{CC}$ & $\mathrm{CT}+\mathrm{TT}$ \\
\hline Smokers & $59(56.70)$ & $45(43.30)$ & $13(76.50)$ & $4(23.50)$ \\
Non-smokers & $28(80.00)$ & $7(20.00)$ & $58(61.70)$ & $36(38.30)$ \\
P value & \multicolumn{2}{c}{$0.01^{*}$} & $2.01(0.61-6.66)$ \\
OR $(95 \% \mathrm{CI})$ & $2.16(1.07-4.35)$ &
\end{tabular}

*Pearson's Chi-square

Overexpression of LSINCTs, especially LSINCT5, in breast and ovarian tumor tissues were also shown by Silva et al. (13). The role of chemical carcinogens on the prognosis/ promotion of lung cancer was determined in several investigations, while in the study by Hoffmannd \& Hecht, upregulation of LSINCT5 was also measured (19). Aberrant expression of LSINCT5 transcript was seen in gastric cell lines and also colorectal cancer tissues (20). In both cancers, a direct correlation was seen between the phenotype and the level of LSINCT5 expression (20). Oncogenic activity of LSINCT5 in breast and gastric cancer was determined by knocking out the gene coding for LSINCTs, which resulted in cell growth and proliferation inhibition $(13,20)$.

One of the limitations of this study was not being able to check the expression of LSINCT5 before and after exposure of bladder cell lines to NNK. Therefore, further studies are needed for confirming the expression deregulation of LSINCT5 in bladder cancer.

\section{Conclusion}

LSINCT5 does not seem to act as a trigger of bladder carcinoma, although it might be an indicator predicting the disease among smokers.

\section{Acknowledgements}

The data reported in this study were extracted from the thesis entitled "Association of polymorphisms rs2962586 \& rs2935641 in lsinct5 sequence with bladder cancer susceptibility" by Mahla Nazari, MSc student in Molecular Genetics in Islamic Azad University, Arsanjan Branch, Arsanjan, Iran. The authors appreciate Dr. Aminsharifi (urologist)and ICR staff for collaborating in sampling procedure and clinical evaluation.

\section{Conflict of interest}

Authors declare no conflict of interest.

\section{Authors' Contributions}

This study was designed and directed by NM and Gh A 
NM as the principal investigator provided conceptual and technical guidance for all aspects of the ptojects. NM performed molecular experiments. NM performed the statistical analysis and data interpretation. NM drafting the manuscript and performed critical revision helping NM.

\section{Support/Funding}

The study was supported by Islamic Azad University, Arsanjan Branch.

\section{References}

1. Sexton WJ, Wiegand LR, Correa JJ, Politis C, Iravani Dickinson S, Kang LC. Bladder Cancer: A Review of Non-Muscle Invasive Disease. Cancer Control. 2010; 17(4):256-68. PMID: 20861813.

2. Burger M, Catto JW, Dalbagni G, Grossman HB, Herr H, Karakiewicz P, et al. Epidemiology and Risk Factors of Urothelial Bladder Cancer. Eur Urol. 2013; 63(2):234-241. PMID: 22877502.

3. Knowles MA, Hurst CD. Molecular biology of bladder cancer: new insights into pathogenesis and clinical diversity. Nat Rev Cancer. 2015; 15:25-41. PMID: 25533674

4. Fajkovic H, Halpern JA, Cha EK, Bahadori A, Chromecki TF, Karakiewicz PI, et al. Impact of gender on bladder cancer incidence, staging, and prognosis. World J Urol. 2011; 29:457-463. PMID: 21656173

5. Freedman ND, Silverman DT, Hollenbeck AR, Schatzkin A, Abnet CC. Association between smoking and risk of bladder cancer among men and women. JAMA. 2011; 306:737-745. doi: 10.1001/jama.2011.1142. PMID: 21846855

6. Rushton L, Bagga S, Bevan R, Brown TP, Cherrie JW, Holmes $\mathrm{P}$, et al. Occupation and cancer in Britain. Br J Cancer. 2010; 102:1428-1437. PMID: 20424618

7. Gibb EA, Brown CJ, Lam WL. The functional role of long noncoding RNA in human carcinomas. Mol Cancer. 2011; 10:38. PMID: 21489289

8. Taft RJ, Pang KC, Mercer TR, Dinger M, Mattick JS. Noncoding RNAs: regulators of disease. J Pathol. 2010; 220(2):126139. PMID: 19882673.

9. Prensner JR, Chinnaiyan AM. The emergence of lncRNAs in cancer biology. Cancer Discov. 2011; 1:391-407. PMID: 22096659.
10. Perez DS, Hoage TR, Pritchett JR, Ducharme-Smith AL, Halling ML, Ganapathiraju SC, et al. Long, abundantly expressed non-coding transcripts are altered in cancer. Hum Mol Genet. 2008; 17(5):642-655. PMID: 18006640.

11. Bhartiya D, Pa K, Ghosh S, Kapoor S, Jalali S, Panwar B. lncRNome: a comprehensive knowledgebase of human long noncoding RNAs. Database (Oxford). 2013; 2013:bat034. PMID: 23846593 .

12. Silva JM, Boczek NJ, Berres MW, Ma X, Smith DI. LSINCT5 is overexpressed in breast and ovarian cancer and affects cellular proliferation. RNA Biol. 2011; 8(3):496-505. PMID: 21532345.

13. Silva JM, Perez DS, Pritchett JR, Halling ML, Tang H, Smith DI. Identification of long stress-induced non-coding transcripts that have altered expression in cancer. Genomics. 2010; 95:355-362. PMID: 20214974.

14. Ye F, Wang L, Castillo-Martin M, McBride R, Galsky M D, Zhu J, et al. Biomarkers for bladder cancer management: present and future. Am J Clin Exp Urol. 2014; 2(1):1-14. PMID: 25374904.

15. Ariel I, Sughayer M, Fellig Y, Pizov G, Ayesh S, Podeh D, et al. The imprinted $\mathrm{H} 19$ gene is a marker of early recurrence in human bladder carcinoma. Mol Pathol. 2000; 53(6):320-3. PMID: 11193051

16. Wang XS, Zhang Z, Wang HC, Cai JL, Xu QW, Li MQ, et al. Rapid identification of UCA1 as a very sensitive and specific unique marker for human bladder carcinoma. Clin Cancer Res. 2006; 12(16):4851-4858. PMID: 16914571.

17. Zhu Y, Yu M, Li Z, Kong C, Bi J, Li J, et al. ncRAN, a Newly Identified Long Noncoding RNA, Enhances Human Bladder Tumor Growth, Invasion, and Survival. Urology. 2010; 77(2):510 e511-515. PMID: 21147498.

18. Chung KT. The etiology of bladder cancer and its prevention. J Cancer Sci Ther. 2013; 5(10):346-61.

19. Hoffmannd RA, Hecht SS. The biological significance of tobacco-specific N-nitrosamines: smoking and adenocarcinoma of the lung. Crit Rev Toxicol. 1996; 26:199-211. PMID: 8688161.

20. Xu MD, Qi P, Weng WW, Shen XH, Ni SJ, Dong L, et al. Long non-coding RNA LSINCT5 predicts negative prognosis and exhibits oncogenic activity in gastric cancer. Medicine. 2014; 93(28): e303. PMID: 25526476 